\title{
ECOG Performance Status 4
}

National Cancer Institute

\section{Source}

National Cancer Institute. ECOG Performance Status 4. NCI Thesaurus. Code C105727.

Completely disabled. Cannot carry on any selfcare. Totally confined to bed or chair. 